\title{
The $\operatorname{rm} B$ Gene Is Essential for Formation of Gm2251 in 23S rRNA but Not for Ribosome Maturation in Escherichia coli
}

\author{
J. MATTIAS LÖVGREN AND P. MIKAEL WIKSTRÖM* \\ Department of Molecular Biology, Umeå University, S-901 87 Umeå, Sweden
}

Received 9 May 2001/Accepted 14 September 2001

\begin{abstract}
In Saccharomyces cerevisiae, the rRNA Gm2270 methyltransferase, Pet56p, has an essential role in the maturation of the mitochondrial large ribosomal subunit that is independent of its methyltransferase activity. Here we show that the proposed Escherichia coli ortholog, RImB (formerly YjfH), indeed is essential for the formation of $\mathrm{Gm}$ in position 2251 of $23 \mathrm{~S} \mathrm{rRNA}$. However, a $\Delta \mathrm{rlmB}$ mutant did not show any ribosome assembly defects and was not outgrown by a wild-type strain even after 120 cell mass doublings. Thus, RImB has no important role in ribosome assembly or function in $E$. coli.
\end{abstract}

The assembly of the $50 \mathrm{~S}$ and $30 \mathrm{~S}$ ribosomal subunits has been proposed to be a self-assembly process as demonstrated by the ability to reconstitute in vitro fully active ribosomes from the isolated components (36). However, recent observations indicate that proteins that assist in the formation of ribosomes, besides the ribosomal components, rRNA-processing enzymes, and rRNA-modifying and ribosomal-proteinmodifying enzymes, have to be present in vivo. Indeed, there are at least seven candidates in Escherichia coli: SrmB and DbpA, two DEAD box RNA helicases (14, 15, 26, 33, 37, 46); Era, an essential GTPase (30, 31-34, 41); RimM and RbfA, two proteins associated with free $30 \mathrm{~S}$ subunits but not with $50 \mathrm{~S}$ subunits or $70 \mathrm{~S}$ ribosomes $(5,6,10,27)$; and DnaK and GroEL, two molecular chaperones that at least at high temperature seem important for ribosome maturation $(1,12,42)$. Whether DnaK and GroEL are directly or indirectly involved in the assembly of ribosomes in E. coli is not known.

In Saccharomyces cerevisiae, the Pet56 protein catalyzes 2'$O$-methylation at the universally conserved $\mathrm{G}$ at position 2270 (Gm2270) in the mitochondrial 21S rRNA (43), corresponding to position 2251 of $23 \mathrm{~S}$ rRNA of $E$. coli. Further, pet56 null mutants lack functional mitochondrial ribosomes, indicating that Pet56p is essential for the in vivo assembly of the mitochondrial large ribosomal subunits (43). Recently it was demonstrated that Pet56p variants with amino acid substitutions in the SAM binding site, which abolished methyltransferase activity, could support the in vivo assembly of functional mitochondrial ribosomes, suggesting that Pet56p has a role in ribosome assembly that is independent of its methyltransferase activity (T. L. Mason, personal communication). In E. coli, the protein encoded by the $y j f H$ gene is a putative $2^{\prime}-O$-methyltransferase, based on its similarities to other $2^{\prime}$ - $O$-methyltransferases, especially Pet56p (21). The yjfH gene in $E$. coli encodes a hypothetical protein 243 amino acids in length and is downstream from the $r n r$ gene, encoding RNase R (9). Just upstream from $y j f H$ there are sequences that match those for promoters dependent on $\sigma^{70}$ for transcription initiation, and downstream from $y j f H$ there is a sequence characteristic of

\footnotetext{
* Corresponding author. Mailing address: Department of Molecular Biology, Umeå University, S-901 87 Umeå, Sweden. Phone: 46-907856754. Fax: 46-90-772630. E-mail: Mikael.Wikstrom@micro.umu.se.
}

rho-independent transcriptional terminators. To investigate whether YjfH was the E. coli rRNA Gm2251 methyltransferase, a chromosomal deletion of $y j f H$ was constructed. The 835-bp region upstream from $y j f H$ was amplified by PCR using the oligonucleotides $r n r-\mathrm{F} 1$ and $\Delta y j f H-\mathrm{R} 1$, trimmed with HindIII and SalI, and cloned into the temperature-sensitive plasmid vector pMAK705, yielding plasmid pMW458 (Table 1). The 917-bp region downstream from yjfH was amplified by PCR using the oligonucleotides $\Delta y j f H$-F1 and $y j f J-R 1$, trimmed with SalI and BamHI, and inserted into plasmid pMW458. The resulting plasmid, pMW465, which contains an in-frame deletion that covers all except the first two and last three codons of yjfH replaced by a SalI site, was used to delete the yjfH gene on the chromosome of strain MW100 following the procedure described by Hamilton et al. (23). One of the resulting strains, MW244, was confirmed by PCR analyses to contain the yjfH deletion on the chromosome. A yjfH ${ }^{+}$strain, MW245, was isolated together with MW244 and used as a control. Further, the $y j \mathrm{fH}^{+}$gene was amplified by PCR using the oligonucleotides yjfH-F2 and yjfH-R2, trimmed with EcoRI and HindIII, and cloned into pBAD30, yielding plasmid pMW467. rRNA and tRNA from the yjfH ${ }^{+}$strain MW245, the $\Delta y j f H$ mutant MW244, and the mutant harboring the $y j \mathrm{fH}^{+}$plasmid pMW467 were prepared (13), degraded with nuclease P1 and alkaline phosphatase to nucleosides (17), and analyzed by high-pressure liquid chromatography (HPLC) (16). The $\Delta y j f H$ mutant MW244 did not show any deficiency in the modification of tRNA (data not shown); however, it was found to lack Gm in 23S rRNA (Fig. 1B). This modification deficiency was fully complemented by plasmid pMW467 (Fig. 1C). These findings and the similarity of $\mathrm{YjfH}$ to Pet56p in S. cerevisiae, together with the fact that in E. coli Gm is found in only one position in rRNA, suggest that $\mathrm{YjfH}$ is indeed the E. coli rRNA Gm2251 methyltransferase. Therefore, we rename YjfH RlmB (for "rRNA large-subunit methylation").

RImB is dispensable for fast growth. To examine whether $\mathrm{R} \operatorname{lmB}$ is important for efficient growth, the growth rate at $37^{\circ} \mathrm{C}$ in Luria-Bertani (LB) medium (2) was determined for the $\Delta \operatorname{lm} B$ mutant MW244 and the wild-type strain MW245. The specific growth rate, $k(=\ln 2 / g$, where $g$ is the mass doubling time in hours), of the $\Delta r \operatorname{lm} B$ mutant was identical to that of the $r \operatorname{lm} B^{+}$strain (1.34; standard deviations of 0.021 and 0.031 , 
TABLE 1. Bacterial strains, plasmids, and oligonucleotides

\begin{tabular}{|c|c|c|}
\hline Strain, plasmid, or oligonucleotide & Description & Reference $^{a}$ \\
\hline \multicolumn{3}{|l|}{ Strains } \\
\hline MW100 & Hfr P4X & 47 \\
\hline MW244 & MW100 $\Delta r \operatorname{lm} B$ & \\
\hline MW245 & MW100 $r \operatorname{lm} B^{+}$ & \\
\hline \multicolumn{3}{|l|}{ Plasmids } \\
\hline pBAD30 & bla cat' araC $\mathrm{P}_{\mathrm{BAD}}$ & 22 \\
\hline pMAK705 & $\operatorname{rep}(\mathrm{Ts})$ cat & 23 \\
\hline pMW458 & rep(Ts) cat 'rnr & \\
\hline pMW465 & rep(Ts) cat 'rnr $\Delta r l m B$ yjfI yjfJ' & \\
\hline pMW467 & bla cat' araC $\mathrm{P}_{\mathrm{BAD}^{-}}-\mathrm{rlmB}$ & \\
\hline \multicolumn{3}{|l|}{ Oligonucleotides } \\
\hline$r n r-\mathrm{F} 1$ & 5'-TTTTAAGCTTGGAAGAGATGCTGCAACTGG-3' & \\
\hline$\Delta y j f H-\mathrm{R} 1$ & 5'-GCTGCGCTGGTCGACGCTCATTAATGTACTCGTTG-3' & \\
\hline$\Delta y j f H-F 1$ & 5'-CATTAATGAGCGTCGACCAGCGCAGCTAATTTCTCAG-3' & \\
\hline yjfJ-R1 & 5'-TTTTGGATCCAACACTTGCTCTTCAGCGG-3' & \\
\hline yjfH-F2 & 5'-TTTTGAATTCGGATAAACGTAGTGCATCAGG-3' & \\
\hline yjfH-R2 & 5'-TTTTAAGCTTACGTAATTATCTTACCAGCTATAG-3' & \\
\hline
\end{tabular}

${ }^{a}$ Unless otherwise noted, the origin was this study.

respectively). Further, no difference between the two strains was observed in their ability to grow at $21,30,37$, and $44^{\circ} \mathrm{C}$ on rich medium plates or at 30,37 , and $42.5^{\circ} \mathrm{C}$ on medium $\mathrm{E}$ plates containing glucose. Also, stationary-phase cell culture density, measured as optical density at $600 \mathrm{~nm}$, and survival in stationary phase, monitored by viable count determinations, after 24 and $48 \mathrm{~h}$ of incubation at $37^{\circ} \mathrm{C}$ in LB medium did not differ between the two strains (data not shown). To test the ability of the $\Delta \operatorname{rm} B$ mutant to grow in competition with the $r \operatorname{lm} B^{+}$strain over the whole range of the growth cycle, the two strains were grown separately in $\mathrm{LB}$ medium at $37^{\circ} \mathrm{C}$ with shaking to stationary phase, at which the optical density at 600 nm was 5.1 for both strains. Equal amounts of stationary-phase cultures of mutant and wild-type cells were mixed, diluted $10^{6}$-fold in LB medium, and incubated for $24 \mathrm{~h}$. The dilution and incubation steps of the mixed culture were repeated five times, and samples were taken at the start and after each cycle and plated on rich medium. To determine the ratio of $\Delta r \operatorname{lm} B$ cells to $r \mathrm{lmB}^{+}$cells in the mixed culture, 48 colonies from each sampling time were subjected to PCR with oligonucleotides $r n r-\mathrm{F} 1$ and $y j f H$-R2. Even after six cycles, corresponding to more than 120 cell doublings, approximately $50 \%$ of the cells in the mixed culture were still $\Delta r \operatorname{lm} B$ mutants (data not shown). Thus, the lack of RlmB did not confer any disadvantage to the mutant cells in their competition with $\operatorname{rm} B^{+}$cells.

RImB is not important for ribosome maturation. Since pet56 mutants of $S$. cerevisiae that lack the rRNA Gm2270 methyltransferase are deficient in the maturation of mitochondrial large ribosomal subunits, we examined whether RlmB was essential for assembly of ribosomes in E. coli. Polysome extracts of strains MW244 $(\Delta \mathrm{rlm} B)$ and MW245 $\left(\mathrm{rlm} \mathrm{B}^{+}\right)$were prepared (40) and fractionated by sucrose gradient centrifugation (39). No differences between the two strains were observed with respect to the amounts of ribosomal subunits, 70S ribosomes, or polysomes (data not shown). To detect any subtle deficiency in ribosome maturation of the $\Delta \operatorname{rm} B$ mutant, the kinetics of ribosome assembly were studied by pulse-labeling techniques. Log-phase cultures of the two strains grown in rich
MOPS medium (35) lacking uracil were labeled with $\left[{ }^{3} \mathrm{H}\right]$ uridine for 1 and $2 \mathrm{~min}$. Cellular extracts were prepared and analyzed by sucrose gradient centrifugation under conditions that dissociated the $70 \mathrm{~S}$ ribosomes into $50 \mathrm{~S}$ and $30 \mathrm{~S}$ subunits (29). The amounts of 50S subunit assembly intermediates in the two strains were indistinguishable at both 1 and 2 min of labeling (data not shown). Furthermore, when the maturation of the 50S subunits was probed by primer extension analysis of the 5' end of 23S rRNA (6), no increased accumulation of precursors to $23 \mathrm{~S}$ rRNA was observed in the $\Delta r m B$ mutant (data not shown). These findings strongly suggest that RlmB is not important for ribosome maturation in E. coli.

In $E$. coli, $16 \mathrm{~S}$ rRNA contains 11 modified nucleosides, of which 10 are methylated, while $23 \mathrm{~S}$ rRNA contains 23 modified nucleosides, of which 14 are methylated (3). Some of the methylated nucleosides have ribose methylations (2'-O-methylations), whereas others have base methylations. Modified nucleosides are clustered at the functional domains of rRNA, such as the A and P sites of $16 \mathrm{~S}$ rRNA and the peptidyltransferase center of $23 \mathrm{~S}$ rRNA (3). It has been proposed that the modifications could affect rRNA maturation and structure, ribosomal subunit association, tRNA binding, and peptidyltransferase activity; however, little is known about their exact functions. In $E$. coli, three $16 \mathrm{~S}$ rRNA methyltransferases (RsmA [KsgA], RsmB [RrmB], and RsmC) and two 23S rRNA methyltransferases (RrmA and RrmJ [FtsJ]) have been identified. A mutation in the E. coli $k s g A(r s m A)$ gene, encoding the 16S rRNA $\mathrm{m}_{2}^{6} \mathrm{~A} 1518,1519$ methyltransferase (24), leads to a reduced growth rate in some media and a reduced polypeptide-synthetic activity in vitro (25), whereas a disruption of the gene for RsmB, the 16S rRNA m ${ }^{5}$ C967 methyltransferase (19, 44), has no discernible effect on the growth rate of the cells (19). No mutation in $r s m C$, encoding the $16 \mathrm{~S}$ rRNA m² G1207 methyltransferase (45), is available; however, RsmC cannot be essential for ribosome function, since functional $30 \mathrm{~S}$ subunits can be prepared using $16 \mathrm{~S}$ rRNA lacking all modifications (11, 28). A strain that lacks RrmA, the $23 \mathrm{~S}$ rRNA m ${ }^{1} \mathrm{G} 745$ methyltransferase, shows a 1.4-fold-increased mass doubling time, 


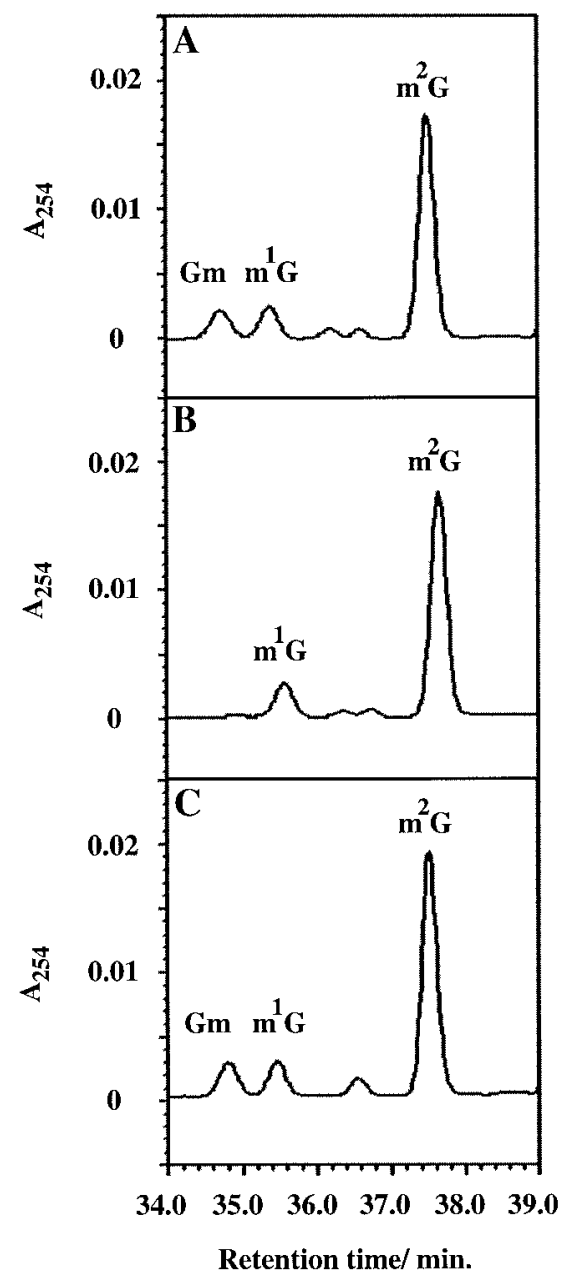

FIG. 1. HPLC analysis of modified nucleosides in rRNA. Only the part of the chromatograms that showed a difference between the strains is shown. (A) Strain MW245 $\left(r \operatorname{lm} B^{+}\right)$; (B) strain MW244 $(\Delta r \operatorname{lm} B) ;(\mathrm{C})$ strain MW244 $(\Delta r \operatorname{lm} B) / \mathrm{pMW} 467\left(\mathrm{rlmB}^{+}\right)$. The indicated nucleosides are 2'-O-methyl guanosine $(\mathrm{Gm}), 1$-methyl guanosine $\left(\mathrm{m}^{1} \mathrm{G}\right)$, and 2-methyl guanosine $\left(\mathrm{m}^{2} \mathrm{G}\right)$. The identity of $\mathrm{Gm}$ was confirmed by spectrum analysis and by comparing the chromatograms with that for a trm $H:: \mathrm{Km}^{\mathrm{r}}$ mutant lacking Gm in tRNA (data not shown; see also reference 38 ).

an increased amount of free ribosomal subunits, and a decreased polypeptide chain elongation rate (20). Similarly, a mutant deficient in RrmJ, the 23S rRNA Um2552 methyltransferase $(4,7)$, has a severe growth disadvantage and a dramatically altered polysome profile $(4,8)$. Since the $\Delta r \operatorname{rm} B$ mutant studied here showed no growth or ribosome assembly defects, Gm2251 cannot play any essential role in ribosome assembly or function, which is also supported by measurements of the peptidyltransferase activity of reconstituted ribosomes containing in vitro-transcribed 23S rRNA lacking Gm2251 (18). However, we cannot exclude the possibility that Gm2251 has some importance for ribosome function under conditions which we have not tested. Our results also suggest that RlmB itself has no important function in ribosome assembly. This contrasts with the situation in $S$. cerevisiae, where the RlmB counterpart, Pet56p, has an essential function in the maturation of the mitochondrial large ribosomal subunit that is independent of its methyltransferase activity (43; Mason, personal communication). In comparison to RlmB, Pet56p has an N-terminal extension of 143 amino acids. Conceivably, the maturation function of Pet56p might reside in this part of the protein, explaining why the $\Delta r \operatorname{lm} B$ mutant was not deficient in ribosome maturation. This maturation function might be completely absent in E. coli or might be performed by another protein or by 23S rRNA.

We thank Kerstin Jacobsson for analyzing RNA by HPLC. We are grateful to Thomas L. Mason for communicating data on Pet56p prior to publication. We thank Olof P. Persson, Glenn R. Björk, and Tord G. Hagervall for stimulating discussions and comments on the manuscript.

This work was supported by the Swedish Natural Science Research Council (B-BU 9911), the Carl Trygger Foundation, and the Magnus Bergvall Foundation.

\section{REFERENCES}

1. Alix, J.-H., and M.-F. Guérin. 1993. Mutant DnaK chaperones cause ribosome assembly defects in Escherichia coli. Proc. Natl. Acad. Sci. USA 90: 9725-9729.

2. Bertani, G. 1951. Studies on lysogenesis. I. The mode of phage liberation by lysogenic Escherichia coli. J. Bacteriol. 62:293-300.

3. Björk, G. R. 1987. Modification of stable RNA, p. 719-731. In F. C. Neidhardt, J. L. Ingraham, K. B. Low, B. Magasanik, M. Schaechter, and H. E. Umbarger (ed.), Escherichia coli and Salmonella typhimurium: cellular and molecular biology, vol. 2. American Society for Microbiology, Washington, D.C.

4. Bugl, H., E. B. Fauman, B. L. Staker, F. Zheng, S. R. Kushner, M. A. Saper, J. C. Bardwell, and U. Jakob. 2000. RNA methylation under heat shock control. Mol. Cell 6:349-360.

5. Bylund, G. O., B. C. Persson, L. A. C. Lundberg, and P. M. Wikström. 1997. A novel ribosome-associated protein is important for efficient translation in Escherichia coli. J. Bacteriol. 179:4567-4574.

6. Bylund, G. O., L. C. Wipemo, L. A. C. Lundberg, and P. M. Wikström. 1998. RimM and RbfA are essential for efficient processing of 16S rRNA in Escherichia coli. J. Bacteriol. 180:73-82.

7. Caldas, T., E. Binet, P. Bouloc, A. Costa, J. Desgres, and G. Richarme. 2000. The FtsJ/RrmJ heat shock protein of Escherichia coli is a $23 \mathrm{~S}$ ribosomal RNA methyltransferase. J. Biol. Chem. 275:16414-16419.

8. Caldas, T., E. Binet, P. Bouloc, and G. Richarme. 2000. Translational defects of Escherichia coli mutants deficient in the $\mathrm{Um}_{2552}$ 23S ribosomal RNA methyltransferase RrmJ/FTSJ. Biochem. Biophys. Res. Commun. 271:714718.

9. Cheng, Z. F., Y. Zuo, Z. Li, K. E. Rudd, and M. P. Deutscher. 1998. The vacB gene required for virulence in Shigella flexneri and Escherichia coli encodes the exoribonuclease RNase R. J. Biol. Chem. 273:14077-14080.

10. Dammel, C. S., and H. F. Noller. 1995. Suppression of a cold-sensitive mutation in 16S rRNA by overexpression of a novel ribosome-binding factor, RbfA. Genes Dev. 9:626-637.

11. Denman, R., D. Negre, P. R. Cunningham, K. Nurse, J. Colgan, C. Weitzmann, and J. Ofengand. 1989. Effect of point mutations in the decoding site (C1400) region of $16 \mathrm{~S}$ ribosomal RNA on the ability of ribosomes to carry out individual steps of protein synthesis. Biochemistry 28:1012-1019.

12. Eı Hage, A., M. Sbaï, and J. H. Alix. 2001. The chaperonin GroEL and other heat-shock proteins, besides DnaK, participate in ribosome biogenesis in Escherichia coli. Mol. Gen. Genet. 264:796-808.

13. Emilsson, V., and C. G. Kurland. 1990. Growth rate dependence of transfer RNA abundance in Escherichia coli. EMBO J. 9:4359-4366.

14. Fuller-Pace, F. V. 1994. RNA helicases: modulators of RNA structure. Trends Cell Biol. 4:271-274.

15. Fuller-Pace, F. V., S. M. Nicol, A. D. Reid, and D. P. Lane. 1993. DbpA: a DEAD box protein specifically activated by $23 \mathrm{~S}$ rRNA. EMBO J. 12:36193626.

16. Gehrke, C. W., and K. C. Kuo. 1990. Ribonucleoside analysis by reversedphase high performance liquid chromatography, p. 3-72. In C. W. Gehrke and K. C. Kuo (ed.), Chromatography and modification of nucleosides, part A: analytical methods for major modified nucleosides. Elsevier, Amsterdam, The Netherlands.

17. Gehrke, C. W., K. C. Kuo, R. A. McCune, K. O. Gerhardt, and P. F. Agris. 1982. Quantitative enzymatic hydrolysis of tRNAs: reversed-phase highperformance liquid chromatography of tRNA nucleosides. J. Chromatogr. 230:297-308.

18. Green, R., and H. F. Noller. 1996. In vitro complementation analysis localizes $23 \mathrm{~S}$ rRNA posttranscriptional modifications that are required for Esche- 
richia coli 50S ribosomal subunit assembly and function. RNA 2:1011-1021.

19. Gu, X. R., C. Gustafsson, J. Ku, M. Yu, and D. V. Santi. 1999. Identification of the 16S rRNA m ${ }^{5} \mathrm{C} 967$ methyltransferase from Escherichia coli. Biochemistry 38:4053-4057.

20. Gustafsson, C., and B. C. Persson. 1998. Identification of the rrmA gene encoding the 23S rRNA m ${ }^{1} \mathrm{G} 745$ methyltransferase in Escherichia coli and characterization of an $\mathrm{m}^{1} \mathrm{G} 745$-deficient mutant. J. Bacteriol. 180:359-365.

21. Gustafsson, C., R. Reid, P. J. Greene, and D. V. Santi. 1996. Identification of new RNA modifying enzymes by iterative genome search using known modifying enzymes as probes. Nucleic Acids Res. 24:3756-3762.

22. Guzman, L. M., D. Belin, M. J. Carson, and J. Beckwith. 1995. Tight regulation, modulation, and high-level expression by vectors containing the arabinose $\mathrm{P}_{\mathrm{BAD}}$ promoter. J. Bacteriol. 177:4121-4130.

23. Hamilton, C. M., M. Aldea, B. K. Washburn, P. Babitzke, and S. R. Kushner. 1989. New method for generating deletions and gene replacements in Escherichia coli. J. Bacteriol. 171:4617-4622.

24. Helser, T. L., J. E. Davies, and J. E. Dahlberg. 1972. Mechanism of kasugamycin resistance in Escherichia coli. Nat. New Biol. 235:6-9.

25. Igarashi, K., K. Kishida, K. Kashiwagi, I. Tatokoro, T. Kakegawa, and S. Hirose. 1981. Relationship between methylation of adenine near the $3^{\prime}$ end of $16-\mathrm{S}$ ribosomal RNA and the activity of 30-S ribosomal subunits. Eur. J. Biochem. 113:587-593.

26. Iggo, R., S. Picksley, J. Southgate, J. McPheat, and D. P. Lane. 1990 Identification of a putative RNA helicase in E. coli. Nucleic Acids Res. 18:5413-5417.

27. Jones, P. G., M. Mitta, Y. Kim, W. Jiang, and M. Inouye. 1996. Cold shock induces a major ribosomal-associated protein that unwinds double-stranded RNA in Escherichia coli. Proc. Natl. Acad. Sci. USA 93:76-80.

28. Krzyzosiak, W., R. Denman, K. Nurse, W. Hellmann, M. Boublik, C. W. Gehrke, P. F. Agris, and J. Ofengand. 1987. In vitro synthesis of 16S ribosomal RNA containing single base changes and assembly into a functional 30S ribosome. Biochemistry 26:2353-2364.

29. Lindahl, L. 1975. Intermediates and time kinetics of the in vivo assembly of Escherichia coli ribosomes. J. Mol. Biol. 92:15-37.

30. Lu, Q., and M. Inouye. 1998. The gene for 16S rRNA methyltransferase $(k s g A)$ functions as a multicopy suppressor for a cold-sensitive mutant of era, an essential RAS-like GTP-binding protein in Escherichia coli. J. Bacteriol. 180:5243-5246.

31. Meier, T. I., R. B. Peery, S. R. Jaskunas, and G. Zhao. 1999. 16S rRNA is bound to era of Streptococcus pneumoniae. J. Bacteriol. 181:5242-5249.

32. Nashimoto, H. 1993. Non-ribosomal proteins affecting the assembly of ribosomes in Escherichia coli, p. 185-195. In K. H. Nierhaus, F. Franceschi, A. R. Subramanian, V. A. Erdmann, and B. Wittman-Liebold (ed.), The transla- tional apparatus. Plenum Press, New York, N.Y.

33. Nashimoto, H., A. Miura, H. Saito, and H. Uchida. 1985. Suppressors of temperature-sensitive mutations in a ribosomal protein gene, rpsL (S12), of Escherichia coli K12. Mol. Gen. Genet. 199:381-387.

34. Nashimoto, H., and H. Uchida. 1985. DNA sequencing of the Escherichia coli ribonuclease III gene and its mutations. Mol. Gen. Genet. 201:25-29.

35. Neidhardt, F. C., P. L. Bloch, S. Pedersen, and S. Reeh. 1977. Chemical measurement of steady-state levels of ten aminoacyl-transfer ribonucleic acid synthetases in Escherichia coli. J. Bacteriol. 129:378-387.

36. Nierhaus, K. H. 1991. The assembly of prokaryotic ribosomes. Biochimie 73:739-755.

37. Nishi, K., F. Morel-Deville, J. W. B. Hershey, T. Leighton, and J. Schnier. 1988. An eIF-4A-like protein is a suppressor of an Escherichia coli mutant defective in 50S ribosomal subunit assembly. Nature 336:496-498.

38. Persson, B. C., G. Jäger, and C. Gustafsson. 1997. The spoU gene of Escherichia coli, the fourth gene of the spoT operon, is essential for tRNA (Gm18) 2'-O-methyltransferase activity. Nucleic Acids Res. 25:4093-4097.

39. Powers, T., and H. F. Noller. 1990. Dominant lethal mutations in a conserved loop in 16S rRNA. Proc. Natl. Acad. Sci. USA 87:1042-1046.

40. Ron, E. Z., R. E. Kohler, and B. D. Davis. 1966. Polysomes extracted from Escherichia coli by freeze-thaw-lysozyme lysis. Science 153:1119-1120.

41. Sayed, A., S. Matsuyama, and M. Inouye. 1999. Era, an essential Escherichia coli small G-protein, binds to the $30 \mathrm{~S}$ ribosomal subunit. Biochem. Biophys. Res. Commun. 264:51-54.

42. Sbaï, M., and J. H. Alix. 1998. DnaK-dependent ribosome biogenesis in Escherichia coli: competition for dominance between the alleles dnaK756 and nnaK $^{+}$. Mol. Gen. Genet. 260:199-206.

43. Sirum-Connolly, K., and T. L. Mason. 1993. Functional requirement of a site-specific ribose methylation in ribosomal RNA. Science 262:1886-1889.

44. Tscherne, J. S., K. Nurse, P. Popienick, H. Michel, M. Sochacki, and J. Ofengand. 1999. Purification, cloning, and characterization of the 16S RNA $\mathrm{m}^{5} \mathrm{C} 967$ methyltransferase from Escherichia coli. Biochemistry 38: 1884-1892.

45. Tscherne, J. S., K. Nurse, P. Popienick, and J. Ofengand. 1999. Purification, cloning, and characterization of the 16 S RNA m2G1207 methyltransferase from Escherichia coli. J. Biol. Chem. 274:924-929.

46. Tsu, C. A., and O. C. Uhlenbeck. 1998. Kinetic analysis of the RNA-dependent adenosinetriphosphatase activity of DbpA, an Escherichia coli DEAD protein specific for 23S ribosomal RNA. Biochemistry 37:16989-16996.

47. Wikström, P. M., A. S. Byström, and G. R. Björk. 1988. Non-autogenous control of ribosomal protein synthesis from the trmD operon in Escherichia coli. J. Mol. Biol. 203:141-152. 